\title{
Comparing the availability, price, variety and quality of fruits and vegetables across retail outlets and by area-level socio-economic position
}

\author{
Anna Millichamp* and Danielle Gallegos \\ School of Public Health, Queensland University of Technology, Victoria Park Road, Kelvin Grove, Brisbane, \\ QLD 4059, Australia
}

Submitted 26 December 2010: Final revision received 28 January 2012: Accepted 7 February 2012: First published online 20 March 2012

\begin{abstract}
Objective: To explore whether area-level socio-economic position or the form of retail stream (conventional $v$. farmers' market) is associated with differences in the price, availability, variety and quality of a range of fresh fruit and vegetables. Design: A multi-site cross-sectional pilot study of farmers' markets, supermarkets and independent fruit and vegetable retailers. Each was surveyed to assess the price, availability, variety and quality of fifteen fruit and eighteen vegetable items. Setting: Retail outlets were located in south-east Queensland.

Subjects: Fifteen retail outlets were surveyed (five of each retail stream).

Results: Average basket prices were not significantly different across the socioeconomic spectrum, but prices in low socio-economic areas were cheapest. Availability, variety and quality did not differ significantly across levels of socio-economic position; however, the areas with the most socio-economic disadvantage scored poorest for quality and variety. Supermarkets had significantly better fruit and vegetable availability than farmers' markets, although price, variety and quality scores were not different across retail streams. Results demonstrate a trend to fruit and vegetable prices being more expensive at farmers' markets, with the price of the fruit basket being significantly greater at the organic farmers' market compared with the non-organic farmers' markets.

Conclusions: Neither area-level socio-economic position nor the form of retail stream was significantly associated with differences in the availability, price, variety and quality of fruit and vegetables, except for availability which was higher in supermarkets than farmers' markets. Further research is needed to determine what role farmers' markets can play in affecting fruit and vegetable intake.
\end{abstract}

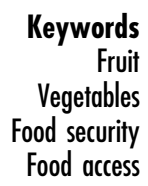

Consumption of an adequate quantity and variety of fruit and vegetables (F\&V) is strongly linked to the achievement of good health, whereas inadequate consumption is associated with chronic disease ${ }^{(1-3)}$. Australia's national dietary guidelines specifically support the consumption of a variety of $F \& V$ with the recognition that inadequate $\mathrm{F} \& \mathrm{~V}$ consumption is responsible for $2 \cdot 1 \%$ of Australia's total disease burden, representing significant avoidable health-care costs ${ }^{(4)}$.

Dietary behaviour is complex and although social, environmental, economic and individual factors have been identified as key determinants ${ }^{(5)}$, it remains poorly understood. People of low socio-economic position (SEP) are least likely to comply with dietary guideline recommendations when purchasing and consuming food ${ }^{(1,6-9)}$ and, consequently, experience a disproportionate burden of nutrition-related ill-health ${ }^{(10)}$. While it has been proposed that differences in food price, availability, accessibility and affordability may play a role in the observed dietary inequalities $^{(11)}$, studies examining the underlying cause(s) in Australia have produced inconclusive results ${ }^{(6,11-13)}$. Cost-effective strategies that reduce dietary inequalities are urgently required $^{(14)}$.

Farmers' markets (FM) are predominantly fresh food markets that operate regularly within a community where farmers (and often retailers) sell produce and associated products directly to consumers. The number of FM in Australia has increased rapidly in recent years and while up-to-date annual revenue figures are not available, in 2004, based on figures from seventeen Australian FM, it was estimated that annual revenues of all FM were approximately \$AUD 40 million $^{(15)}$. Despite more recent national estimates not being available, a Victorian survey of FM in 2010 estimated that annual revenue from Victorian FM alone was approximately \$AUD 113 million $^{(16)}$, demonstrating the significant growth that has occurred in 
FM in recent years. In comparison, total consumer expenditure on food and in Australia in 2003-04 was \$AUD 89 billion $^{(17)}$. FM aim to provide customers with regular supplies of fresh food, access to improved nutrition and contribute to the economic, social and health capital of the host community ${ }^{(18)}$. It has been proposed that FM could also contribute to a reduction in obesity and food security by playing a role in educating consumers on food and nutrition, improving cooking skills, and contributing to the development of coherent communities via provision of positive social connections ${ }^{(19-21)}$. Non-causal mechanisms such as education, income and food-related values must also be considered as mediating the relationship between FM patronage and the opportunity for better health outcomes. A small Australian study has indicated that FM may play a role in increasing the consumption of $\mathrm{F} \& \mathrm{~V}$ for regular attendees ${ }^{(20)}$.

FM may therefore offer potential as a public heath nutrition strategy, particularly for improving the dietary intakes of lower socio-economic groups. However, it has been proposed that as FM have become fashionable, they have started selling boutique, expensive food products, becoming a place for the 'food elite' to do their grocery shopping and potentially excluding certain social groups $^{(22)}$.

There has been some research, both in Australia and internationally, suggesting that customers perceive FM produce to be of higher quality ${ }^{(15,20,23,24)}$. It has also been claimed that FM may offer a price advantage over other retail streams ${ }^{(19)}$. However, there has been little research that confirms the existence of such benefits and whether any associated advantage varies by area-level SEP. The objective of the present pilot study was to address this gap by collecting preliminary data on whether or not either area-level SEP or the form of retail stream (FM, supermarket or independent F\&V retailer) is associated with differences in the price, availability, variety and quality of a range of fresh, seasonal F\&V.

\section{Methods}

The study was a multi-site, cross-sectional pilot study of five FM, five supermarkets and five independent F\&V retailers operating in five south-east Queensland suburbs conducted in August and September 2009. Ethics approval was obtained from the Queensland University of Technology Human Research Ethics Committee.

\section{Sample design}

A list of FM located in south-east Queensland was compiled based on an Internet search, of which seventeen met the preliminary inclusion criteria of being predominantly a fresh produce market ( $\geq 80 \%$ food products); running weekly or fortnightly; and operating for longer than 6 months.
The final selection of five FM was based on the need to represent a range of SEP areas, market manager consent and logistical requirements. The Index of Relative Socioeconomic Disadvantage (IRSD) was used as a proxy for classifying each suburb's SEP. The IRSD is one of the Australian Bureau of Statistic's Socio-Economic Indexes for Areas (SEIFA), which is a suite of four indices that rank the socio-economic characteristics of Australian geographic areas ${ }^{(25)}$. The IRSD measures relative disadvantage, incorporating seventeen measures of the economic and social resources of people and households within a geographical area ${ }^{(26)}$. A high score is interpreted as a relative lack of disadvantage ${ }^{(26)}$.

\section{Data collection and survey instruments}

For each FM, two conventional retail outlets (one large supermarket and one independent F\&V retailer) within $5 \mathrm{~km}$ by road of the FM were identified via an Internet search. The closest conventional retailers that provided consent were included. One FM, supermarket and F\&V retailer in each of the five geographical areas (making a total of fifteen retail outlets) were surveyed on the price, availability, variety and quality of fifteen fruit and eighteen vegetable items. Table 1 reports the location and SEP classification for each of the five areas studied. Of note, the FM located in ISRD decile 8 (high SEP) was an organic FM, while all others dealt largely in non-organic produce with minor amounts of organic produce available also. As a pilot study, sample size was small with low statistical power. Statistical significance was set at $P=0.05$.

The produce items included in the survey were based on those included in the Queensland Government's Healthy Food Basket Survey ${ }^{(27)}$ and seasonality considerations (Table 2). Price, availability, variety and quality were scored for a fruit basket (fifteen items), a vegetable basket (eighteen items) and a combined F\&V basket (thirty-three items). While prior consent was obtained from store management, retailers were not aware of the date that the audit was to be conducted, minimizing the chance that produce offerings and prices could be manipulated.

The two predictor variables employed in the present study were area-level SEP and store type. Criterion variables

Table 1 Geographical location and SEP classification of the areas studied, south-east Queensland, August-September 2009

\begin{tabular}{lcc}
\hline Geographic area* $^{*}$ & IRSD decile & SEP classification \\
\hline Brisbane (outer suburb) & 1 & Low \\
Moreton Bay & 3 & Low \\
Brisbane (inner suburb) & 4 & Mid \\
Gold Coast & 7 & High \\
Brisbane (inner suburb) & 8 & High \\
\hline
\end{tabular}

SEP, socio-economic position; ISRD, Index of Relative Socio-economic Disadvantage.

*In each geographic area, one farmers' market, one supermarket and one independent fruit and vegetable retailer were surveyed. 
Table 2 Fruit and vegetables included in the survey*

\begin{tabular}{|c|c|c|c|}
\hline Fruit basket & Unit & Vegetable basket & Unit \\
\hline Apples & $1 \mathrm{~kg}$ & Broccoli & $1 \mathrm{~kg}$ \\
\hline Oranges & $1 \mathrm{~kg}$ & Cabbage & 1 head \\
\hline Bananas & $1 \mathrm{~kg}$ & Capsicum (pepper) & $1 \mathrm{~kg}$ \\
\hline Grapes & $1 \mathrm{~kg}$ & Carrot & $1 \mathrm{~kg}$ \\
\hline Kiwi fruit & $1 \mathrm{~kg}$ & Cauliflower & 1 head \\
\hline Mandarins & $1 \mathrm{~kg}$ & Cucumber & $1 \mathrm{~kg}$ \\
\hline Pears & $1 \mathrm{~kg}$ & Green beans & $1 \mathrm{~kg}$ \\
\hline Strawberries & $1 \mathrm{~kg}$ & Lettuce (e.g. iceberg) & 1 head \\
\hline Lemon & $1 \mathrm{~kg}$ & Mushroom & $1 \mathrm{~kg}$ \\
\hline Avocado & 1 piece & Onion & $1 \mathrm{~kg}$ \\
\hline Paw paw (papaya) & $1 \mathrm{~kg}$ & Potato & $1 \mathrm{~kg}$ \\
\hline Pineapple & 1 whole & Pumpkin & 1 piece \\
\hline Watermelon & $1 \mathrm{~kg}$ & Sweet corn & 1 ear \\
\hline Rockmelon (cantaloupe) & 1 whole & Sweet potato & $1 \mathrm{~kg}$ \\
\hline \multirow[t]{4}{*}{ Mango } & 1 piece & Tomato & $1 \mathrm{~kg}$ \\
\hline & & Zucchini & $1 \mathrm{~kg}$ \\
\hline & & Asian greens (e.g. bok choy, choy sum) & 1 bunch \\
\hline & & Eggplant & $1 \mathrm{~kg}$ \\
\hline
\end{tabular}

${ }^{*}$ The combined fruit and vegetable basket included the items in both the fruit basket and the vegetable basket.

included price, availability, variety and quality scores for the fruit, the vegetable and the combined F\&V baskets. Area deprivation characteristics (as ascertained by the IRSD) were used to classify the selected geographic areas as either low (areas located in decile 1 and decile 3), mid (area located in decile 4) or high (areas located in decile 7 and decile 8) SEP areas (Table 1). The major factor informing this reclassification was adequate representation of various points on the socio-economic spectrum.

Availability of the fifteen fruit items and the eighteen vegetable items was reported as 'available' (score 1) or 'not available' (score 0), a reporting method used in similar earlier surveys ${ }^{(12,27)}$. From this, an availability score was calculated, with a higher score representing a greater availability. When an item was not available in-store, it was not possible to determine a score for price, variety or quality. Price was recorded by noting the cheapest dollar price and pricing unit for an available produce type. At certain retail outlets, the prices of some items were only available on a per unit basis and as weighing the produce was not feasible, an average fruit or vegetable weight was obtained from the NUTTAB 2006 database using the software FoodWorks Professional 2007 (Xyris Software, Brisbane, Australia). This method was used to determine a per kilogram price, facilitating appropriate statistical comparisons. Pumpkin was excluded from the final price analyses as the recorded price data did not clearly distinguish between varieties with significantly different sizes, hindering meaningful price comparisons. Variety was scored by counting the number of different varieties that were available for each of the different types of $\mathrm{F} \& \mathrm{~V}$ in each of the baskets. For example, if six different apple varieties were available at a store the allocated score was 6. 'Variety' in this survey referred only to the different cultivar of $F \& V$, rather than the same variety packaged differently. Quality was scored as $1=$ 'poor quality', $2=$ 'satisfactory quality' and $3=$ 'good quality', where a higher score represented a greater degree of quality, based on the visual appearance of the item. Taste was not included in the determination of quality. While this classification of quality was based on those used in the Healthy Food Access Basket Survey Guidelines ${ }^{(27)}$, the present survey differed as it used three, rather than two, quality categories. This provided an additional level of quality information, distinguishing between acceptable ('satisfactory') produce and exceptional ('good') produce. For example, a poor quality score would be given when there was a significant amount of mould or damage evident; a satisfactory classification may include a majority of individual pieces that are damage free but include several items that are damaged, bruised or mouldy; and good quality classification was assigned when all the items in the section appeared fresh, free of damage and mould. Data collection was completed for all items by one researcher to facilitate consistency of measurement.

\section{Statistical analyses}

Audit data were analysed using the Predictive Analytics SoftWare (PASW) statistical software package version $18 \cdot 0$ (2009; SPSS Inc., New York, NY, USA). To preserve the size of the data set, where an item was missing, the mean price for the variable was imputed. Fifteen fruits and seventeen vegetables were included in the final analyses for price, while fifteen fruits and eighteen vegetables were included for availability, variety and quality analyses. Basket scores were normally distributed except for the price of the fruit basket, the price of the F\&V basket and the three availability basket scores. The price scores for the fruit and the F\&V baskets were amenable to log transformations, whereas the availability scores were not. Where log transformations were conducted, geometric mean and the anti-logged log scale confidence interval 
Table 3 Availability, price, variety and quality basket scores by area-level SEP, south-east Queensland, August-September 2009

\begin{tabular}{|c|c|c|c|c|c|c|c|c|c|}
\hline & \multicolumn{2}{|c|}{$\begin{array}{c}\text { Low SEP } \\
\text { (2 geographic areas) }\end{array}$} & \multicolumn{2}{|c|}{$\begin{array}{c}\text { Mid SEP } \\
\text { (1 geographic area) }\end{array}$} & \multicolumn{2}{|c|}{$\begin{array}{c}\text { High SEP } \\
\text { (2 geographic areas) }\end{array}$} & \multicolumn{2}{|c|}{ Test statistics } & \multirow[b]{2}{*}{$P$ value ${ }^{*}, t$} \\
\hline & Median & Range & Median & Range & Median & Range & $\chi^{2}$ & $d f$ & \\
\hline \multicolumn{10}{|l|}{ Availability } \\
\hline Fruit basket & $14 \cdot 50$ & $10 \cdot 00-15 \cdot 00$ & $15 \cdot 00$ & $13 \cdot 00-15 \cdot 00$ & $13 \cdot 00$ & $13 \cdot 00-15 \cdot 00$ & $0 \cdot 764$ & $2(n 15)$ & $0.682^{*}$ \\
\hline Vegetable basket & $17 \cdot 50$ & $17 \cdot 00-18 \cdot 00$ & $18 \cdot 00$ & $18 \cdot 00-18 \cdot 00$ & $18 \cdot 00$ & $18 \cdot 00-18 \cdot 00$ & $5 \cdot 250$ & $2(n 15)$ & $0 \cdot 720^{*}$ \\
\hline \multirow[t]{2}{*}{ F\&V basket } & $32 \cdot 00$ & $27 \cdot 00-33 \cdot 00$ & 33.00 & $31 \cdot 00-33 \cdot 00$ & 33.00 & $31 \cdot 00-33 \cdot 00$ & 1.672 & $2(n 15)$ & $0 \cdot 433^{*}$ \\
\hline & Mean & SD & Mean & SD & Mean & SD & $F$ & $d f$ & \\
\hline \multicolumn{10}{|l|}{ Price (\$AUD) } \\
\hline Fruit basketł & $45 \cdot 20$ & $38 \cdot 31,53 \cdot 35$ & $52 \cdot 27$ & $40 \cdot 72,67 \cdot 11$ & $56 \cdot 61$ & $42 \cdot 09,76 \cdot 15$ & $1 \cdot 707$ & $2(n 12)$ & $0.223 t$ \\
\hline Vegetable basket & $54 \cdot 01$ & 12.57 & $60 \cdot 46$ & $5 \cdot 22$ & $70 \cdot 17$ & 20.08 & $1 \cdot 658$ & $2(n 12)$ & $0.231 t$ \\
\hline F\&V basketł & $98 \cdot 15$ & $80 \cdot 24,120 \cdot 05$ & $112 \cdot 74$ & $95 \cdot 26,133.42$ & $125 \cdot 57$ & $97 \cdot 38,161 \cdot 94$ & $2 \cdot 252$ & $2(n 12)$ & $0.148 t$ \\
\hline \multicolumn{10}{|l|}{ Variety } \\
\hline Fruit basket & $23 \cdot 80$ & $3 \cdot 86$ & $27 \cdot 45$ & 3.09 & $26 \cdot 59$ & $5 \cdot 16$ & 0.941 & $2(n 12)$ & $0.417 t$ \\
\hline Vegetable basket & $37 \cdot 99$ & $9 \cdot 12$ & $36 \cdot 67$ & $6 \cdot 66$ & $43 \cdot 12$ & $7 \cdot 90$ & $0 \cdot 847$ & $2(n 12)$ & $0.453 t$ \\
\hline F\&V basket & $61 \cdot 79$ & $11 \cdot 53$ & $64 \cdot 12$ & $9 \cdot 70$ & $69 \cdot 70$ & $11 \cdot 07$ & 0.797 & $2(n 12)$ & $0.473 t$ \\
\hline \multicolumn{10}{|l|}{ Quality } \\
\hline Fruit basket & $36 \cdot 75$ & $5 \cdot 87$ & $41 \cdot 00$ & $4 \cdot 00$ & $40 \cdot 88$ & $3 \cdot 22$ & $1 \cdot 467$ & $2(n 12)$ & $0.269 t$ \\
\hline Vegetable basket & $44 \cdot 62$ & $7 \cdot 32$ & $49 \cdot 00$ & $2 \cdot 65$ & $50 \cdot 50$ & $2 \cdot 43$ & $2 \cdot 093$ & $2(n 12)$ & $0 \cdot 166 t$ \\
\hline F\&V basket & $81 \cdot 37$ & $12 \cdot 45$ & $90 \cdot 00$ & $1 \cdot 73$ & $91 \cdot 38$ & $4 \cdot 48$ & $2 \cdot 263$ & $2(n 12)$ & $0 \cdot 147 t$ \\
\hline
\end{tabular}

SEP, socio-economic position; F\&V, fruit and vegetable.

*Kruskal-Wallis test.

tANOVA.

¥Natural log transformation performed; anti-log of the log scale mean (geometric mean) and $95 \% \mathrm{Cl}$ are presented.

are reported ${ }^{(28)}$. For parametric data, one-way ANOVA was employed to explore relationships between SEP or store type and basket scores. For non-parametric data, the Kruskal-Wallis statistical test was used to explore the relationships between SEP or store type and basket scores, with post hoc testing employing the Mann-Whitney $U$ test. A comparison was made between basket prices at the single organic FM and the non-organic FM. Correlation testing was used to assess interrelationships between criterion variables.

\section{Results}

The average availability, price, variety and quality scores for the fruit basket, vegetable basket and F\&V basket across different levels of socio-economic disadvantage are shown in Table 3. Availability, price, variety and quality scores were not significantly different across levels of SEP. However, prices in low-SEP areas tended to be cheapest and increased with higher levels of SEP, while quality and variety scores were lowest in the more socio-economically disadvantaged areas and increased as relative advantage increased.

Table 4 presents the average scores for availability, price, variety and quality for the fruit basket, vegetable basket and F\&V basket across the three types of retail outlets. The median availability scores for the fruit basket $(P=0 \cdot 011)$ and the $\mathrm{F} \& \mathrm{~V}$ basket $(P=0 \cdot 027)$ were significantly different across store types. Post hoc analysis evaluating pairwise differences among the groups, controlling for Type 1 error across tests using the Bonferroni approach, revealed that availability score was significantly higher in supermarkets than FM.

Price, variety and quality scores were not significantly different across store types. Exploration of the observed trends indicated that customers tended to pay the most for all three baskets when they shopped at FM and the least when they shopped at independent F\&V retailers. Average variety scores trended highest at supermarkets, followed by independent $\mathrm{F} \& \mathrm{~V}$ retailers and then FM. Customers interested in quality were potentially better off shopping for the vegetable basket at FM but the quality of the fruit basket was assessed as highest at supermarkets. Quality scores for all three baskets were poorest at independent $\mathrm{F} \& \mathrm{~V}$ retailers.

A comparison was made between the prices of the baskets at the single organic FM compared with the four (predominantly) non-organic FM (data not shown). Basket prices were higher at the organic FM than at the non-organic FM. The fruit basket was \$AUD 27.63 more expensive than the next most expensive FM (\$AUD $45 \cdot 30$ organic FM $v$. \$AUD $17 \cdot 67$ highest price nonorganic FM), the vegetable basket was \$AUD $18 \cdot 21$ more expensive (\$AUD 69.62 v. \$AUD 51.41) and the F\&V basket was \$AUD 48.51 more expensive (\$AUD $114.92 v$. \$AUD 66・41).

Spearman's rank-order correlation assessed the interrelationships between the scores of availability, price, variety and quality for all three basket types (data not shown). Price and quality scores were significantly correlated for all three baskets (fruit: $r_{s}(13)=0.589$, $P=0.021 ;$ vegetable: $r_{s}(13)=0.532, \quad P=0.041 ; \quad \mathrm{F} \& \mathrm{~V}$ : $\left.r_{s}(13)=0 \cdot 640, P=0 \cdot 010\right)$. Quality and availability were 
Table 4 Availability, price, variety and quality basket scores by retail outlet, south-east Queensland, August-September 2009

\begin{tabular}{|c|c|c|c|c|c|c|c|c|c|}
\hline & \multicolumn{2}{|c|}{$\begin{array}{l}\text { Farmers' market } \\
(n 5)\end{array}$} & \multicolumn{2}{|c|}{$\begin{array}{l}\text { Supermarket } \\
\qquad(n 5)\end{array}$} & \multicolumn{2}{|c|}{$\begin{array}{l}\text { Independent F\&V retailer } \\
(n \text { 5) }\end{array}$} & \multicolumn{2}{|c|}{ Test statistics } & \multirow[b]{2}{*}{$P$ value ${ }^{*}}$, \\
\hline & Median & Range & Median & Range & Median & Range & $\chi^{2}$ & df & \\
\hline \multicolumn{10}{|l|}{ Availability } \\
\hline Fruit basket & $13 \cdot 00$ & $10 \cdot 00-14 \cdot 00 \ddagger$ & $15 \cdot 00$ & $15 \cdot 00-15 \cdot 00 \ddagger$ & $15 \cdot 00$ & $12 \cdot 00-15 \cdot 00$ & 8.975 & $2(n 15)$ & $0.011^{*}$ \\
\hline Vegetable basket & $18 \cdot 00$ & $17 \cdot 00-18 \cdot 00$ & $18 \cdot 00$ & $17 \cdot 00-18 \cdot 00$ & $18 \cdot 00$ & $17 \cdot 00-18 \cdot 00$ & 0.00 & $2(n 15)$ & $1 \cdot 000^{*}$ \\
\hline \multirow[t]{2}{*}{ F\&V basket } & $31 \cdot 00$ & $27 \cdot 00-32 \cdot 00 \ddagger$ & 33.00 & $32 \cdot 00-33 \cdot 00 \ddagger$ & 33.00 & $29 \cdot 00-33 \cdot 00$ & $7 \cdot 229$ & $2(n 15)$ & $0.027^{\star}$ \\
\hline & Mean & SD & Mean & SD & Mean & SD & $F$ & df & \\
\hline \multicolumn{10}{|l|}{ Price (\$AUD) } \\
\hline Fruit basket§ & $53 \cdot 38$ & $34 \cdot 12,83 \cdot 51$ & $52 \cdot 79$ & $43 \cdot 32,64 \cdot 33$ & $46 \cdot 86$ & $42 \cdot 48,51 \cdot 68$ & 0.485 & $2(n 12)$ & $0 \cdot 627 \ddagger$ \\
\hline Vegetable basket & $73 \cdot 76$ & $23 \cdot 58$ & $59 \cdot 08$ & 6.38 & $52 \cdot 54$ & 4.85 & $2 \cdot 829$ & $2(n 12)$ & $0.099 \ddagger$ \\
\hline F\&V basket§ & $124 \cdot 52$ & $81 \cdot 92,189 \cdot 27$ & $111 \cdot 77$ & $96 \cdot 39,129 \cdot 59$ & $99 \cdot 24$ & $89 \cdot 26,110 \cdot 31$ & $1 \cdot 430$ & $2(n 2)$ & $0.277 \ddagger$ \\
\hline \multicolumn{10}{|l|}{ Variety } \\
\hline Fruit basket & $25 \cdot 17$ & 3.39 & $27 \cdot 00$ & $6 \cdot 20$ & $24 \cdot 77$ & $3 \cdot 47$ & 0.342 & $2(n 12)$ & $0 \cdot 717 \dagger$ \\
\hline Vegetable basket & $35 \cdot 14$ & $3 \cdot 30$ & $46 \cdot 23$ & $9 \cdot 20$ & $37 \cdot 96$ & $7 \cdot 39$ & $3 \cdot 318$ & $2(n 12)$ & $0 \cdot 710+$ \\
\hline F\&V basket & $60 \cdot 31$ & 5.39 & $73 \cdot 23$ & $13 \cdot 37$ & $62 \cdot 73$ & $9 \cdot 19$ & $2 \cdot 379$ & $2(n 12)$ & $0 \cdot 135+$ \\
\hline \multicolumn{10}{|l|}{ Quality } \\
\hline Fruit basket & $38 \cdot 44$ & $5 \cdot 12$ & $41 \cdot 40$ & $3 \cdot 58$ & $37 \cdot 91$ & $5 \cdot 65$ & 0.747 & $2(n 12)$ & $0.494 t$ \\
\hline Vegetable basket & $50 \cdot 48$ & $2 \cdot 39$ & $47 \cdot 10$ & $4 \cdot 01$ & $45 \cdot 97$ & $8 \cdot 34$ & 0.903 & $2(n 12)$ & $0.431 t$ \\
\hline F\&V basket & 88.91 & $7 \cdot 05$ & $88 \cdot 50$ & $6 \cdot 67$ & $83 \cdot 88$ & $13 \cdot 77$ & 0.412 & $2(n 12)$ & $0.671 \dagger$ \\
\hline
\end{tabular}

F\&V, fruit and vegetable.

*Kruskal-Wallis test.

tANOVA.

¥Significant differences within a row $(P<0.05)$ between pairs of medians according to the Mann-Whitney $U$ test.

$\S$ Natural log transformation performed; anti-log of the log scale mean (geometric mean) and $95 \% \mathrm{Cl}$ are presented.

positively correlated for the fruit basket $\left(r_{s}(13)=0 \cdot 518\right.$, $P=0.048)$ and the vegetable basket $\left(r_{s}(13)=0.542\right.$, $P=0 \cdot 037)$. For the $\mathrm{F} \& \mathrm{~V}$ basket there was a significant correlation between availability and variety scores $\left(r_{s}(13)=0 \cdot 674, P=0 \cdot 006\right)$.

\section{Discussion}

The present study has explored the variation in price, availability, variety and quality of a selection of F\&V between conventional (supermarkets and independent F\&V retailers) and non-conventional (FM) retail streams and across area-level SEP. Availability of the F\&V basket was significantly different between retail streams, with supermarkets scoring better for availability than FM. The organic FM was found have significantly higher prices for the fruit basket compared with the other FM. While further significant differences were elusive in the current pilot study, an analysis of the trends indicated that potential differences may exist for price, variety and quality of $\mathrm{F} \& \mathrm{~V}$ across areas of differing levels of socioeconomic disadvantage and for availability, price, variety and quality of F\&V across different retail streams. Trends indicated that although areas with greater levels of socioeconomic disadvantage may have access to cheaper F\&V than more advantaged areas, the variety and the quality of F\&V on offer were poorer. A trend towards higher prices at FM saw FM customers paying the highest price for the all three baskets whereas those shopping at independent $\mathrm{F} \& \mathrm{~V}$ retailers were paying the least. In terms of variety, supermarkets scored highest for all baskets with little difference in variety between FM and independent F\&V retailers. While quality was not different between store types, F\&V quality scores at FM and supermarkets were higher than at independent $F \& V$ retailers. Quality and price scores were significantly positively correlated for all baskets.

Similar to the results of the present study, several Australian studies have found that lower-SEP areas were not disadvantaged in terms of price of nutritious foods ${ }^{(6,11,12)}$. However, it is recognized that such results do not provide insight into the ability of those people with low SEP to afford a dietary intake in line with nutritional recommendations ${ }^{(6,12,14)}$. There is evidence that dietary decisions when made in the context of sustained budgetary constraints are driven by maximizing calories per dollar spent, which potentially translates into reduced purchasing of $\mathrm{F} \& \mathrm{~V}^{(29,30)}$. Other barriers not related to price may potentially prevent lower-SEP groups, and possibly the general population, consuming adequate $\mathrm{F} \& \mathrm{~V}$ such as nutrition knowledge ${ }^{(31)}$, taste preferences $^{(32)}$, cooking abilities and storage facilities ${ }^{(9)}$.

The trend towards poorer F\&V variety and quality in areas with higher levels of socio-economic disadvantage is important as environmental factors, whether real or perceived, potentially contribute to decreased dietary compliance among people living in relatively disadvantaged areas $^{(14,33,34)}$. While earlier work in Melbourne reported a degree of area-level disadvantage in relation to produce availability and variety ${ }^{(11)}$, two Brisbane-based studies did not find similar associations ${ }^{(6,12)}$. Turrell's study ${ }^{(6)}$ 
did not concentrate on F\&V alone and looked only at availability in supermarkets, and both Winkler et al. ${ }^{(12)}$ and Turrell et $a l^{(7)}$ only considered Brisbane (the capital city), rather than south-east Queensland. South-east Queensland may experience a different degree of residential segregation along socio-economic lines than Brisbane alone, which could then impact on observed socio-economic disparities in F\&V availability and variety.

No Australian studies known to the authors have explored whether or not fresh produce in lower-SEP areas is of a different quality to that available in more advantaged areas. The trend observed in the present study towards poorer quality scores in lower-SEP areas is concerning. Poor-quality produce may erode price advantages observed in relatively disadvantaged socioeconomic areas as poorer-quality produce may not keep as long, may be less visually appealing and potentially does not taste as good as higher-quality produce.

While no Australian studies were identified that explore differentials in fresh $\mathrm{F} \& \mathrm{~V}$ price, variety, availability and quality among conventional and non-conventional retail streams, international research has found that the type of (conventional) retail outlet influences the price and availability of food ${ }^{(35,36)}$. Also, organic produce is often priced at a premium compared with non-organic produce ${ }^{(37)}$ and therefore it is reasonable to assume that for some households organic F\&V may not be easily affordable. It is therefore unsurprising that the prices of the baskets were higher at the organic FM (which also was located in a highSEP area) than at the non-organic FM. It is acknowledged that the higher price of produce at the organic market affects the comparisons made of the basket prices across store types and SEP levels. Regardless of whether FM sell only premium priced organic produce or not, it has been argued that FM have become places for socio-economically advantaged people to shop ${ }^{(22)}$, casting doubt over whether the promotion of FM as a public health nutrition strategy aiming to reduce dietary intake inequalities would indeed be successful.

Perceptions impact food purchasing decisions ${ }^{(14)}$. Whereas quality for the three baskets was not found to be different between retail streams in the present study, information collected in parallel with that discussed here found that the majority of customers believed FM sold produce superior in taste, quality, variety and delivered more value compared with conventional retail streams (A Millichamp and D Gallegos, unpublished results). Assessment of quality is difficult ${ }^{(38)}$. Research has demonstrated that while price is not a good indicator of 'objective' quality, particularly in relation to food products, consumers frequently use price to infer quality ${ }^{(38)}$. As average prices in the current study tended to be highest at FM, this may explain the perception of better quality and 'value' that has been associated with FM (A Millichamp and D Gallegos, unpublished results).
The trend towards poorer variety scores found in the present study for the vegetable and the $\mathrm{F} \& \mathrm{~V}$ baskets at FM compared with conventional retail outlets potentially reflects the commitment of FM to offer local produce only. FM often market themselves as supporting local agriculture and therefore are unlikely to consistently match the large range in produce offered by conventional retailers, who are able to import and stock a wide range of $F \& V$ varieties from all over Australia and the world.

The limitations of the current study include the inability to make interpretations at the individual level due to the ecologic study design, the inability to infer causal relationships and the lack of generalizability. As a pilot study, statistical power was lacking, hindering the ability to obtain significant findings. It is acknowledged that mean imputation is not a perfect way to deal with missing values and can reduce variable variance and influence correlations $^{(39)}$. Although conventional retails stores were selected that were as close as possible to the FM within each geographic area, the actual distances between these shopping alternatives may not reflect shopping alternatives for those residents who lack access to a private motor vehicle. Of note, access to independent transport has been found to be more important in determining food access than living in a food desert ${ }^{(13)}$. Geographic areas vary in their ethnic diversity and this may impact on produce availability, price, quality and variety. Ethnicity was not directly considered in the present research; however, the use of commonly available items is likely to have reduced the impact of such differences.

Additional limitations in the study include the reliance on appearance to assess quality and the fact that the single assessor was not blinded to product price. While a defined assessment protocol was followed to improve the reliability of the quality score, it cannot be excluded that the assessment of quality was impacted by the prices observed by the researcher. In addition, the quality score did not attempt to capture other important quality attributes, such as taste, which is an important factor in determining food consumption ${ }^{(40)}$. Finally, as mentioned above, the inclusion of one organic FM which had higher produce prices alongside four non-organic FM may have confounded subsequent price comparisons. Future research would benefit from a more complete assessment of produce quality and a more in-depth consideration of the differences between organic and non-organic produce prices.

Study strengths include the attempt that was made to consider two conventional and one non-conventional (FM) F\&V retail streams. The majority of past Australian research in this area has focused on conventional retail streams $^{(6,11,12)}$. Today's food retail environment presents consumers with more diverse retail options, clearly demonstrated by the increase in FM seen in Australia $^{(41)}$ and abroad $^{(42)}$. 
Further research is required to determine whether areas that experience relatively greater levels of socioeconomic disadvantage actually experience poorer availability, variety and quality of fresh F\&V when both conventional and non-conventional retail streams are considered. The present pilot study drew on a small sample of F\&V retailers and focused on only some of the elements that impact food choice. It is recommended that further study is carried out with a larger sample of both conventional and non-conventional retailers, to improve our understanding of how these retailer outlets influence the food environment, purchasing decisions and dietary intake and how this varies by area-level SEP.

\section{Conclusions}

The pilot study described here found that while lowerSEP areas showed a trend towards cheaper $F \& V$, this price advantage may possibly be eroded by the trend towards poorer variety and quality of the produce available in these areas. It also demonstrated that conventional retailers and FM are not significantly different in the price, variety and quality of $F \& V$, but that availability of F\&V was better at supermarkets than FM.

\section{Acknowledgements}

This research received no specific grant from any funding agency in the public, commercial or not-for-profit sectors. No conflicts of interest are reported. A.M. designed the research project, carried out data collection and data analysis, and wrote the manuscript. D.G. acted in a supervisory capacity throughout the research project, providing guidance on design, data collection, manuscript formation and editing.

\section{References}

1. Australian Institute of Health and Welfare (2008) Australia's Health 2008: The Eleventh Biennial Health Report of the AIHW. Canberra: Australian Government.

2. Krebs-Smith SM \& Kantor LS (2001) Choose a variety of fruits and vegetables daily: understanding the complexities. J Nutr 131, 2 Suppl., S487-S502.

3. Savige GS (2001) Can food variety add years to your life? Asia Pac J Clin Nutr 11, Suppl. 3, S637-S641.

4. National Health and Medical Research Council (2003) Dietary Guidelines for Australian Adults. Canberra: Australian Government.

5. Vita P, Moxon J \& Macoun E (2001) Increasing the consumption of vegetables and fruit: a national public health call to action. NSW Public Health Bull 12, 9-12.

6. Turrell G (1996) Structural, material and economic influences on the food purchasing choices of socioeconomic groups. Aust N Z J Public Health 20, 611-617.

7. Turrell G, Hewitt B, Patterson C et al. (2002) Socioeconomic differences in food purchasing behaviour and suggested implications for diet-related health promotion. J Hum Nutr Diet 15, 355-364.
8. Mishra G, Ball K, Arbuckle J et al. (2002) Dietary patterns of Australian adults and their association with socioeconomic status: results from the 1995 National Nutrition Survey. Eur J Clin Nutr 56, 687-693.

9. Giskes K, Turrell G, Patterson C et al. (2002) Socioeconomic differences in fruit and vegetable consumption among Australian adolescents and adults. Public Health Nutr 5, 663-669.

10. Philip TJW, Nelson M, Ralph A et al. (1997) The contribution of nutrition to inequalities in health. BMJ 314, 1545-1549.

11. Ball K, Timperio A \& Crawford D (2009) Neighbourhood socioeconomic inequalities in food access and affordability. Health Place 15, 578-585.

12. Winkler E, Turrell G \& Patterson C (2006) Does living in a disadvantaged area entail limited opportunities to purchase fresh fruit and vegetables in terms of price, availability, and variety? Findings from the Brisbane Food Study. Health Place 12, 741-748.

13. Coveney J \& O'Dwyer LA (2009) Effects of mobility and location on food access. Health Place 15, 45-55.

14. Inglis V, Ball K \& Crawford D (2008) Socioeconomic variations in women's diets: what is the role of perceptions of the local food environment? J Epidemiol Community Health 62, 191-197.

15. Coster M \& Kennon N (2005) New Generation Farmers' Markets in Rural Communities. Canberra: Australian Government Rural Industries and Development Corporation.

16. Victorian Farmers' Market Association (2010) Market Research Project Report. Abbotsford: Victorian Farmers' Market Association.

17. Department of Agriculture Fisheries and Forestry (2004) Australian Food Statistics 2004. Canberra: Commonwealth of Australia.

18. Australian Farmers' Market Association (2009) Australian Farmers' Market Association Website. http://www.farmers markets.org.au (accessed April 2009).

19. Australian Farmers' Market Association (2004) Sustainable Cities 2025 - Creating Space and a Place for Farmers' Markets in Australian Cities. Submission to the Parliament of Australia Standing Committee of Environment and Heritage, 17/05/2009. Potts Point: Australian Farmers' Market Association.

20. Payet J, Gilles M \& Howat P (2005) Gascoyne growers market: a sustainable health promotion activity developed in partnership with the community. Aust J Rural Health 13, 309-314.

21. Fisher A (1999) Hot Peppers and Parking Lot Peaches: Evaluating Farmer's Markets in Low Income Communities. Venice, CA: Community Food Coalition.

22. Holloway L \& Kneafsey M (2000) Reading the space of the farmers' market: a preliminary investigation from the UK. Sociol Ruralis 40, 285-299.

23. Smithers J, Lamarche J \& Joseph AE (2008) Unpacking the terms of engagement with local food at the farmers' market: insights from Ontario. J Rural Stud 24, 337-350.

24. Feagan R, Morris D \& Krug K (2004) Niagara Region Farmers' Markets: local food systems and sustainability considerations. Local Environ 9, 235-254.

25. Australian Bureau of Statistics (2008) Socio-Economic Indexes for Areas (SEIFA 2006). Catalogue no. 2033.0. 55.001. Canberra: ABS.

26. Australian Bureau of Statistics (2008) 2039.0 - Information Paper: An Introduction to Socio-Economic Indexes for Areas (SEIFA), 2006. Canberra: ABS.

27. Queensland Health (2006) The 2006 Healthy Food Access Basket (HFAB) Survey. Brisbane: Queensland Health.

28. Altman D, Gore S, Gardner M et al. (1983) Statistical guidelines for contributions to medical journals. B Med J (Clin Med Ed) 286, 1489-1493.

29. Drewnowski A, Monsivais P, Maillot M et al. (2007) Low-energy-density diets are associated with higher diet 
quality and higher diet costs in French adults. J Am Diet Assoc 107, 1028-1032.

30. Brimblecombe JK \& O'Dea K (2009) The role of energy cost in food choices for an Aboriginal population in northern Australia. Med J Aust 190, 549-551.

31. Hollis JF, Carmody TP, Connor SL et al. (1986) The Nutrition Attitude Survey: associations with dietary habits, psychological and physical well-being, and coronary risk factors. Health Psychol 5, 359-374.

32. Turrell G (1998) Socioeconomic differences in food preference and their influence on healthy food purchasing choices. J Hum Nutr Diet 11, 135-149.

33. Kamphuis CBM, Giskes K, de Bruijin G et al. (2006) Environmental determinants of fruit and vegetable consumption among adults: a systematic review. Br J Nutr 96, 620-635.

34. Dibsdall L, Lambert N, Bobbin R et al. (2003) Low-income consumers' attitudes and behaviour toward access, availability and motivation to eat fruit and vegetables. Public Health Nutr 6, 159-168.

35. Block D \& Kouba J (2006) A comparison of the availability and affordability of a market basket in two communities in the Chicago area. Public Health Nutr 9, 837-845.

36. Cummins S \& Macintyre S (2002) A systematic study of an urban foodscape: the price and availability of food in Greater Glasgow. Urban Stud 39, 2115-2130.
37. Oberholtzer L, Dimitri C \& Greene C (2005) Price Premiums Hold On As US Organic Produce Market Expands. Electronic Outlook Report VGS-308-01. http://www.ers.usda.gov/ publications/vgs/may05/vgs30801/vgs30801.pdf (accessed January 2012).

38. Kirchler E, Fischer F \& Holzl E (2010) Price and its relation to objective and subjective product quality: evidence from the Austrian Market. J Consum Policy 33, 275-286.

39. Gelman A \& Hill J (2006) Data Analysis using Regression and Multilevel/Hierarchical Models. Cambridge: Cambridge University Press; available at www.stat.columbia.edu/ $\sim$ gelman/arm/missing.pdf

40. Garcia-Bailo B, Toguri C, Eny KM et al. (2009) Genetic variation in taste and its influence on food selection. OMICS 13, 69-80.

41. Outer Suburban/Interface Services and Development Committee (2010) Inquiry into Farmers' Markets. East Melbourne: State of Victoria.

42. US Department of Agriculture (2011) Farmers Markets and Local Food Marketing: Farmers Market Growth: 1994-2011. http://www.ams.usda.gov/AMSv1.0/ams.fetchTemplateData. do?template $=$ TemplateS\&leftNav $=$ WholesaleandFarmers Markets\&page $=$ WFMFarmersMarketGrowth\&description $=$ Farmers\%20Market\%20Growth\&acct $=$ frmrdirmkt (accessed September 2011). 